\title{
The Alfieri's edge-to-edge technique for mitral valve repair: from a historical milestone of cardiac surgery to the origin of the transcatheter era
}

\author{
Igor Belluschi, Nicola Buzzatti, Alessandro Castiglioni, Ottavio Alfieri, Michele De Bonis \\ Department of Cardiac Surgery, IRCCS San Raffaele Hospital, Vita-Salute San Raffaele University, Milan 20132, Italy.
}

Correspondence to: Dr. Igor Belluschi, Department of Cardiac Surgery, IRCCS San Raffaele Hospital, Vita-Salute San Raffaele University, Via Olgettina 60, Milan 20132, Italy. E-mail: belluschi.igor@hsr.it

\begin{abstract}
How to cite this article: Belluschi I, Buzzatti N, Castiglioni A, Alfieri O, De Bonis M. The Alfieri's edge-to-edge technique for mitral valve repair: from a historical milestone of cardiac surgery to the origin of the transcatheter era. Mini-invasive Surg 2020;4:58. http://dx.doi.org/10.20517/2574-1225.2020.48
\end{abstract}

Received: 18 May 2020 First Decision: 23 Jun 2020 Revised: 28 Jun 2020 Accepted: 10 Jul 2020 Published: 1 Sep 2020

Academic Editor: Giulio Belli Copy Editor: Cai-Hong Wang Production Editor: Jing Yu

\begin{abstract}
After 30 years since its introduction, the edge-to-edge technique has become one of the most popular and adopted worldwide for surgical repair of mitral regurgitation. The success of this procedure could possibly be explained by its unique simplicity and high level of reproducibility. Indeed, it possesses the ability of being very versatile and it has been used in a wide spectrum of mitral valve pathologies and lesions: from degenerative to functional disease, from posterior to anterior leaflet lesions, including commissural defects. The rapidity of this easy surgical gesture has also enhanced its application in minimally invasive approaches. Finally, it has become a true milestone for the era of transcatheter correction of mitral regurgitation. Here, we describe the history and evolution of this breakthrough in the world of cardiac surgery.
\end{abstract}

Keywords: Mitral valve repair, edge-to-edge technique, Alfieri's stitch, double-orifice

\section{INTRODUCTION}

Mitral valve disease still represents the most frequent valvulopathy ${ }^{[1]}$. Several studies have shown the preference of valve repair over replacement due to reduced peri-operative mortality and improved longterm survival, thus becoming the gold standard for treatment of severe degenerative mitral regurgitation $(\mathrm{MR})^{[2]}$. At the beginning of the 1980's, Professor Alain Carpentier introduced the so-called "French 
correction", the first standardized and reproducible toolbox of surgical techniques to treat mitral valve regurgitation ${ }^{[3]}$. This approach which is based on the reconstruction of the native valve anatomy mainly through the resection of the prolapsing and excessive tissue, has become a surgical landmark for the art of mitral valve repair, providing optimal long-term outcomes, especially in isolated prolapse of the posterior leaflet ${ }^{[4]}$. However, the results of these "anatomical reconstructions" in the setting of anterior, bileaflet and commissural lesions were reported to be less promising ${ }^{[5]}$.

In 1991, the Italian cardiac surgeon Professor Ottavio Alfieri introduced a surgical technique for the repair of mitral regurgitation, named "edge-to-edge" (later known also as the "Alfieri's stitch") ${ }^{[6]}$. This revolutionary method was based upon a "functional" rather than "anatomical" conceptualization of the valve repair. In this way, the application of a suture at the site of the regurgitant jet, between the facing free margins of the anterior and posterior leaflets (usually A2 and $\mathrm{P} 2$ ), creates a "double-orifice" valve without residual prolapse of one or both leaflets. Indeed, the most common indication for the edge-to-edge repair is represented by bileaflet prolapse in the setting of Barlow's, where the excess of myxomatous tissue allows the application of a strong and wide suture, extending along the entire free margins of the central scallops ("central edgeto-edge" or "double orifice repair"). Given the increased risk of systolic anterior motion (SAM) of the anterior mitral leaflet, the iatrogenic fusion of both leaflets by application of the Alfieri's stitch reduces the fluctuation of the anterior leaflet towards the left ventricular outflow tract (LVOT). On the other hand, the closure of the whole commissural area to treat non-central lesions ("paracommissural edge-to-edge") preserves the single orifice configuration of the native valve. In addition, the concomitant use of a complete or partial prosthetic ring decreases the tension on the edge-to-edge suture, allowing for further stabilization of the annulus and enhances the overall durability of the repair.

Simplicity and reproducibility represent the main reasons for the success of the Alfieri's stitch, a truly versatile surgical technique which has been adopted in thousands of patients ${ }^{[7-13]}$. This paves way for a breakthrough in the world of cardiac surgery, particularly in percutaneous mitral valve repair ${ }^{[14]}$.

In this review we will briefly discuss the history of the edge-to-edge mitral valve repair, beginning from its origins, through the initial criticisms, reasons for success, to its ultimate percutaneous evolution.

\section{INDICATIONS FOR MITRAL SURGERY}

As stated by the 2017 ESC guidelines on the treatment of valvular heart disease, surgery (especially repair whenever possible) is indicated in cases of severe symptomatic primary mitral valve regurgitation with left ventricle ejection fraction $>30 \%{ }^{[2]}$. In addition, in asymptomatic patients, the presence of Left Ventricle Ejection Fraction (LVEF) $\leq 60 \%$ or Left Ventricle End Systolic Diameter $\geq 45 \mathrm{~mm}$, atrial fibrillation or a systolic pulmonary pressure $\geq 50 \mathrm{mmHg}$ predict a worse outcome and therefore surgery should be considered as well. Whenever long durability is predicted, early repair is encouraged.

Severe secondary mitral regurgitation in patients undergoing CABG with LVEF $>30 \%$ is another indication for surgery (class I; level C). However, when LVEF is $<30 \%$ but the patient still has an option for revascularization and there is evidence of myocardial viability, surgery should be considered (class IIa; level C). If revascularization is not indicated, surgery may be considered in those patients who remain symptomatic despite optimal medical management (including CRT if indicated) and have a low surgical risk (class IIb; level C).

Compared to replacement, surgical mitral valve (MV) repair has shown optimal early-, mid- and longterm results, with a lower peri-operative mortality rate ${ }^{[15]}$. In experienced centers, at 20 years, the reported MR recurrence rate after repair is around $10 \%{ }^{[16]}$. On the other hand, repair for secondary MR has shown to be less durable, with a significant rate of recurrence at 2 years ${ }^{[17]}$. The presence of echocardiographic 
factors indicating an increased mitral valve deformation (such as coaptation distance $\geq 1 \mathrm{~cm}$; tenting area $>2.5-3 \mathrm{~cm}^{2}$; complex jets etc.) or a high level of local and global LV remodeling account for an unfavorable repair $^{[18]}$.

In the presence of relevant comorbidities and high surgical risk, a percutaneous edge-to-edge procedure may be considered in patients with primary or secondary MR, who remain symptomatic despite optimal medical therapy (including CRT if indicated), with echocardiographic screening required for perioperative risk stratification and assessment of suitability (class IIb; level C). The Heart Team may consider this transcatheter option after careful evaluation of other strategies (i.e., left ventricular assistant devices or heart transplant).

\section{THE IDEA}

At the beginning of the 90's, a young woman who suffered from symptomatic severe mitral valve regurgitation asked Professor Alfieri's to perform her own surgery. However, despite a comprehensible feeling of anxiety and fear of the intervention, another reason justified her melanchony: the unlikelihood of having a pregnancy after surgery. Indeed, her anterior mitral leaflet lesion appeared to be not suitable for a conventional repair. Alternatively, the durability of a bioprosthesis would have been very poor and a mechanical prosthesis would have drammatically increase the risks of a potential pregnancy. It was in this scenario that Professor Alfieri, particularly impressed by the aspiration of the young lady to become a mother, had the intuition of anchoring the prolapsing scallop of the anterior leaflet to the facing segment of the posterior leaflet, which had normal mobility. This concept of a valve with a double-orifice was derived from the world of congenital diseases. Previously, he had occasionally observed that patients with a congenital double-orifice valve rarely had a pathological evolution in regurgitation. In other words, the double-orifice design, derived from "a congenital mistake", would have become now a simple solution to fix complex anatomical mitral valve lesions. Despite the uncertainties of a new surgical procedure, Professor Alfieri obtained the informed consent from the patient and an efficient mitral valve repair was achieved with the novel "Alfieri's Edge-to-Edge" technique. A few years later, the patient gave birth to three healthy children.

\section{THE SURGICAL TECHNIQUE}

Usually, the "double orifice" repair starts with the inspection of the valve and the analysis of the target lesion (see next paragraph). Once the indication for the adoption of the edge-to-edge technique has been identified, the proper repair begins. After identification of the central portion of the valve, the edge-toedge suture (generally 4-0 polypropylene) is placed exactly in the middle of the leaflet and, then, a matress followed by a running suture is extended on both sides (antero-lateral and postero-medial), to cover the regurgitant jet site [Figure 1]. The injection of saline solution helps to test the hydrodynamic competence of the repaired valve. The resulting double-orifice valve area can be directly measured by Hegar dilators (at least $2.5 \mathrm{~cm}^{2}$ for a normal size patient) and assessed by intra-operative trans-oesophageal echocardiography (TOE).

Moreover, the application of a complete or a partial prosthetic ring prevents further annular dilatation. In addition, it helps in reducing the stress on the edge-to-edge thus preserving long-term durability of the repair. Indeed, it has been demonstrated that the absence of an annuloplasty ring is associated with higher repair failure: in a series of 260 patients undergoing edge-to-edge repair, 52 of them did not received an annuloplasty for severe annular calcification $(n=44)$ or absence of annular dilatation $(n=8)$. The 5 -years freedom from reoperation was $92 \%$ and $70 \%$ in those who annuloplasty was performed or not, respectively ${ }^{[19]}$. Similarly, in a series of 61 patients treated with the Alfieri's technique at the beginning of the experience without annuloplasty, the long-term results were not satisfactory: the 12-years the freedom from recurrence of moderate-to-severe MR was $43 \%$ and the freedom from reoperation was $58 \%{ }^{[20]}$. 


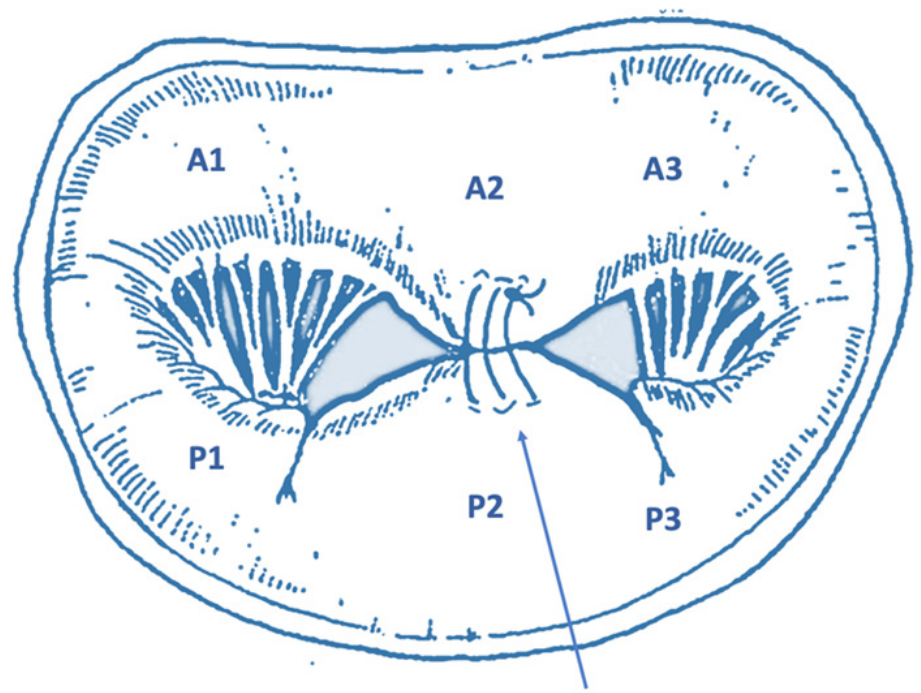

Figure 1. Central edge-to-edge. Schematic representation of the application of the Alfieri's repair applied in the central portion of the mitral valve (A2-P2), originating an artificial double-orifice valve

The introduction of a double-orifice valve, however, has been debated for a long time since it dramatically changes the valve shape and the previous historical concept of the "French correction", by which native valve anatomy should be restored. However, the ability of subsequent computational models to detect that the hemodynamic performance of a double-orifice valve mainly depends on the whole valve area and cardiac output, rather than on the presence of one or two orifices. In this setting, the flow velocity through each orifice corresponds to that of a single orifice with an area which is the sum of the two. It can happen that the prolapsing lesion is placed not exactly at the center of the valve but slightly more laterally or medially. In these cases, the edge-to-edge suture will lead to a valve with two orifices of different sizes. Although the area of the two orifices will be different, the Doppler velocity flow will remain the same in both orifices.

One of the main concerns regarding the edge-to-edge repair was the impact that an artificial doubleorifice valve configuration would have during exercise, particularly in terms of the risk of mitral stenosis. Numerous studies reported that, under exercise testing, despite a physiological increase in transvalvular gradients, the hemodynamics values do not result in pathologic stenosis (mean gradient from $2.8 \pm 1.3$ to $4.6 \pm 1.9 \mathrm{mmHg}$ at rest and exercise, respectively; $P<0.00001)^{[21]}$, and do not differ from varying resection techniques $^{[22]}$.

\section{TARGET LESIONS}

Throughout the past decades, the Alfieri repair has shown to be a very versatile technique, since it fits with a variety of target lesions and valve diseases. Here, we present the main indications of the edge-to-edge technique.

\section{Bileaflet lesion}

Barlow's disease is generally responsible for lesions involving both leaflets. The presence of redundant myxomatous tissue allows the application of wide and deep edge-to-edge stitches, thus reducing the leaflets' height. In addition, converse to longer procedures targeting the chordal/papillary muscle apparatus, it can be easily and quickly performed, thus reducing ischemic time while still achieving excellent results. The first published data showed a low incidence of perioperative mortality $(0.92 \% ; n=6 / 648)$ and good middleterm clinical outcome ( 5 -year survival $92 \% \pm 4.5 \%$; freedom from reoperation $91 \% \pm 4.2 \%)^{[23]}$. Long-term results have confirmed excellent durability with no evidence of late mitral stenosis ${ }^{[2]}$. 


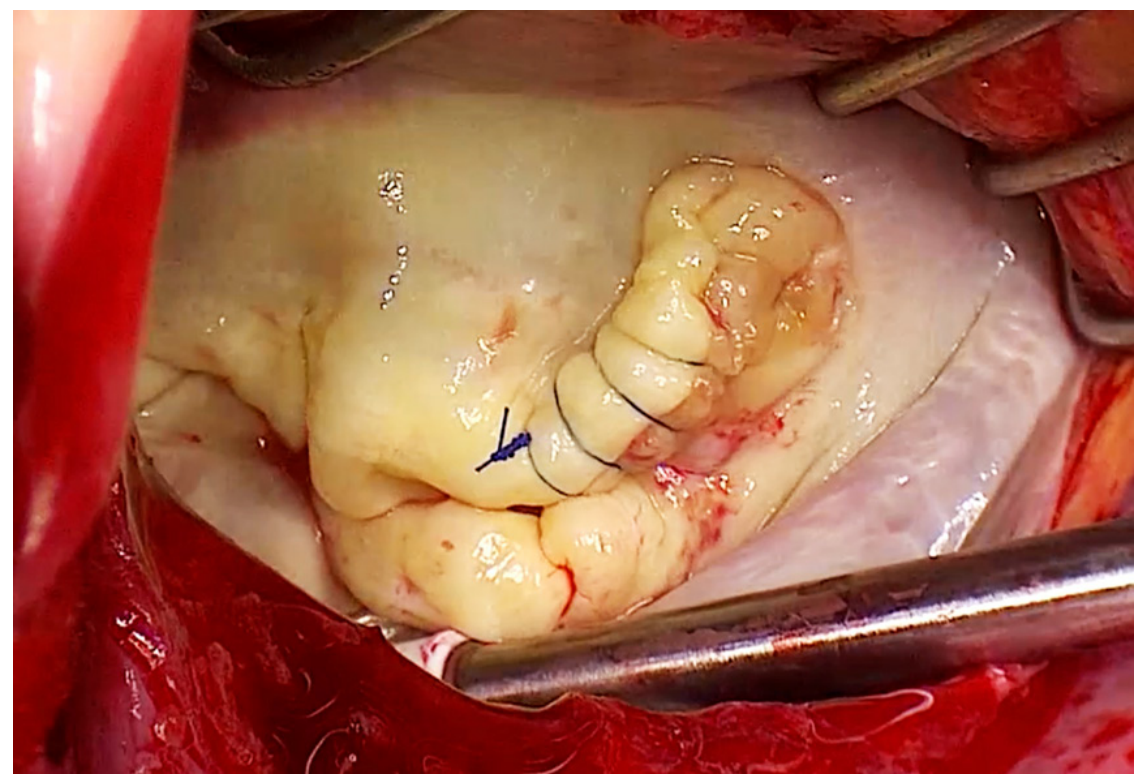

Figure 2. Paracommissural edge-to-edge. Alfieri's technique in a case of a postero-medial commissural prolapse due to previous endocarditis (ring annuloplasty still to be added). In this situation, the configuration of a single-orifice valve is maintained

\section{Anterior leaflet prolapse}

When the prolapsing lesion is limited to the central scallop of the anterior leaflet (A2), the edge-to-edge technique provides excellent late outcomes, thus avoiding the need of artificial chordae implantation ${ }^{[25]}$. In a series of 139 patients, a 17 -year survival rate of $72.4 \% \pm 7.89 \%$, freedom from cardiac death of $90.8 \% \pm$ $4.77 \%$ and freedom from reoperation of $89.6 \% \pm 2.74 \%$ were reported. Recurrence of MR grade $\geq 3+$ was documented in $12.5 \%$ (17/135) of cases. At multivariate analysis, the predictors of MR recurrence include the presence of a greater-than-mild residual MR at discharge (HR: 7.4; 95\%CI: 2.5-21.2; $P=0.001$ ) and the use of a pericardial rather than a prosthetic ring annuloplasty (HR: $2.8 ; 95 \%$ CI: $0.9-8.7 ; P=0.06)^{[26]}$.

\section{Paracommissural edge-to-edge}

Commissural lesions remain very challenging to repair, even for most experienced surgeons [Figure 2]. On the other hand, the application of the edge-to-edge technique can fixate the valve in a few minutes. Indeed, results in 115 patients treated with paracommissural edge-to-edge technique combined with annuloplasty ring showed a 2-year recurrence of severe MR in only 2 patients (1.9\%), again without evidence of mitral stenosis $^{[27]}$. Similarly, the Cleveland Clinic reported encouraging data on more than 100 of patients treated with closure of the prolapsing commissure ${ }^{[28]}$.

\section{Functional mitral valve disease}

Mitral regurgitation in the setting of ischemic or non-ischemic dilated cardiomyopathy is secondary to both apical tenting of the leaflets and annular dilatation in remodeled ventricles. In the presence of moderate tethering and a relatively small ventricle, the application of an undersized annuloplasty using a complete rigid or semirigid ring may be an effective solution. When leaflet tethering is more pronounced (coaptation depth $>1 \mathrm{~cm}$ ), it has been proposed that the association of a central edge-to-edge technique could enhance the durability of the repair. Unfortunately, Bhudia and colleagues showed a 2-year recurrence rate of moderate-to-severe MR post-operatively in secondary MR of $24 \%{ }^{[11]}$. However, in this series the application of flexible bands was probably not enough to support the annulus and prevent its further dilatation, which was the common finding at reoperations. Better results were described by the Alfieri's group, with a 5-year freedom from repair failure of $95 \% \pm 3.4 \%$, significantly higher as compared to that of isolated annuloplasty without edge-to-edge $(77 \% \pm 12.1 \% ; P=0.04)^{[22]}$. 


\section{Systolic anterior motion}

It has been postulated that the edge-to-edge technique may play a role in the prevention of post-repair SAM of the anterior mitral valve leaflet, which can dynamically create LVOT obstruction in the presence of anatomical risk factors. Few series reported such results of the edge-to-edge in this setting, and even less in the context of hypertrophic obstructive cardiomyopathy (HOCM). Mascagni and coworkers adopted the double-orifice technique to treat successfully four patients with post-repair $\operatorname{SAM}^{[30]}$, while Brinster et al. ${ }^{[12]}$ showed optimal results in 20 cases even at 4 years of follow-up without the need for reintervention. In our center, we adopted the edge-to-edge technique to treat 26 HOCM patients in which septal thickness was considered inadequate to allow for a safe and effective myectomy with good outcomes: the 8-year cumulative incidence function (CIF) of reoperation with death as a competing risk was $7.7 \% \pm 5.2 \%{ }^{[31]}$.

\section{Rescue edge-to-edge}

The double-orifice technique, due to the intrinsic versatility and rapidity of its surgical gesture, which is not time-consuming, has proved to be a valid option even as a rescue procedure, which means to improve the initial suboptimal result of a conventional repair, when the attempt to save the valve becomes a "surgeon's nightmare". Gatti et al. ${ }^{[32]}$ described this strategy in 11 patients who underwent other repair techniques and a concomitant final rescue edge-to-edge for residual MR, thus reducing the jet area from $3.0 \pm 0.8 \mathrm{~cm}^{2}$ to $0.7 \pm 0.9 \mathrm{~cm}^{2}(P=0.00014)$, and adding only $14.9 \pm 2.8 \mathrm{~min}$ to the aortic cross-clamp times. Our experience has been very gratifying under those circumstances ${ }^{[33]}$. However, in these challenging scenarios, the efficacy of the edge-to-edge technique may be very difficult to predict, and not surprisingly other authors have reported suboptimal results ${ }^{[34]}$. Finally, particular attention should be given when applying an additional edge-to-edge to a triangular/quadrangular resection: the relative reduction of tissue due to previous resection can be responsible for small final orifices, eventually resulting in mitral stenosis, particularly in cases of wide and deep Alfieri's stitches.

\section{MINIMALLY INVASIVE APPROACH}

The edge-to-edge technique can be easily performed through a minimally invasive approach with relatively short the cross-clamp times, which are generally longer in case of small access and limited surgical view as compared to median sternotomy. An antero-lateral right mini-thoracotomy $(6 \mathrm{~cm})$ is usually performed through the third or fourth intercostal space and a soft tissue retractor is inserted. After surgical TOEguided femoral venous and arterial cannulation, cardiopulmonary bypass is instituted at $28-30{ }^{\circ} \mathrm{C}$. In those patients who require concomitant procedures, such as atrial septal defect closure or tricuspid valve repair, an additional percutaneous cannula may be inserted in the jugular vein. Endoaortic balloon (Heartport, Inc, Redwood City, CA, USA) inserted in the femoral artery under echocardiographic guidance or transthoracic surgical clamps (i.e., the Chitwood clamp, Scanlan International, Inc, Minneapolis, MN, USA; or the Cygnet flexible clamp, Vitalitec, Plymouth, MA, USA) are adopted for aortic cross-clamp. Antegrade intermittent cold blood cardioplegia or crystalloid cardioplegic solutions are administered directly into the aortic root. Access to the mitral valve is generally achieved through a left atriotomy and a left atrial retractor is placed through a parasternal incision. The valve analysis and repair is performed both under direct and video-assisted vision using a $30^{\circ}$ camera.

A robotic approach has been reported as well, since the versatility and simplicity of the double-orifice technique enhances its application ${ }^{[35]}$.

A recent publication showed excellent long-term results (up to 19 years) with minimally invasive edge-toedge repair in myxomatous degenerative mitral valve regurgitation ${ }^{[36]}$. Indeed, analyzing 97 consecutive patients with severe myxomatous mitral regurgitation who underwent mitral valve repair through a right minithoracotomy between 1999 and 2006, it was reported a 16-year overall survival of $95.9 \% \pm 2.02 \%$ (95\%CI: 89.39-98.43). At 16 years, the CIF of cardiac death, with non-cardiac death as a competing risk, 


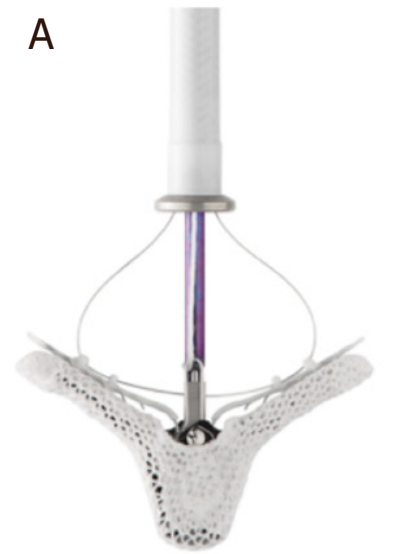

B

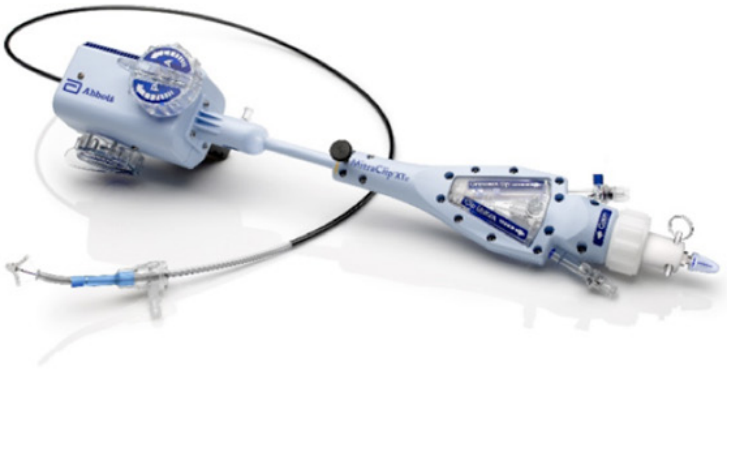

Figure 3. The MitraClip system. On the left, the MitraClip structure with two arms, now $5 \mathrm{~mm}$ longer in the XTR version, and grippers (A); on the right the $24 \mathrm{Fr}$ delivery steerable guiding catheter (B) (Courtesy of Abbott)

was $3.1 \pm 1.75$ (95\%CI: 0.83-8.02). Only 4 patients (4.1\%) were reoperated for recurrent severe mitral regurgitation (MR). At 16 years, $\mathrm{CIF}$ of reoperation and recurrence of $\mathrm{MR} \geq 3+$ with death as a competing risk were $3.1 \% \pm 1.76 \%$ (95\% CI: 0.83-8.02) and 5.6\% $\pm 2.47 \%$ (95\% CI: $2.06-11.83)$ respectively.

It is of pivotal importance that the long-term outcomes are excellent in patients with degenerative MV disease, because current guidelines recommend early repair for asymptomatic patients with severe MR, whenever long durability is predicted ${ }^{[2]}$. Providing the patients with the option of a cosmetically favorable procedure without sacrificing efficacy and long-term durability, will facilitate early surgical correction of MR before the development of LV dysfunction. Indeed, most of the target population for this approach will face a long life-expectancy (the mean age of the series previously reported was $35 \pm 9$ years).

\section{THE ORIGIN OF TRANSCATHETER MITRAL VALVE REPAIR}

Simplicity of the edge-to-edge technique enables the possibility of it being translated into a percutaneous approach and constitutes a milestone in the field of cardiovascular medicine, thus paving the way to an era of transcatheter mitral valve repair ${ }^{[37]}$.

Indeed, the Alfieri's stitch has inspired the development of percutaneous leaflet repair devices such as the MitraClip and the PASCAL systems.

The MitraClip system (Abbott, Chicago, IL, USA) was the first device designed to simulate the surgical edge-to-edge repair. Designed by the Californian start-up Evalve Inc. (purchased by Abbott in 2009), the MitraClip device [Figure 3] was first implanted in $2003^{[38]}$. It has obtained CE mark and FDA approval for treatment of primary MR in 2008 and 2013, respectively. Nowadays, more than 100,000 patients have been treated with the Abbott MitraClip device. After the feasibility study (EVEREST I trial), in 2011 the EVEREST II randomized clinical trial (Endovascular Valve Edge-to-edge REpair Study II trial) reported the outcome of MitraClip compared to surgery in a $2: 1 \mathrm{ratio}^{[39]}$. A total of 279 patients suffering of moderateto-severe or severe $\mathrm{MR}$, both degenerative and functional and with a jet originating from malcoaptation of the A2-P2 scallops, were enrolled. Despite the fact that the transcatheter repair showed less efficacy to reduce MR-grade at 1 -year, it was found to be superior in terms of safety (major adverse events: $15 \%$ clip vs. $48 \%$ surgery; $P<0.001$, almost exclusively driven by difference in blood transfusion) and demonstrated similar clinical outcome improvements (primary composite endpoint were $55 \%$ and $73 \%$ for the percutaneous edge-to-edge and surgical option, respectively; $P=0.007)$. The 5-year follow-up revealed persistence of a significant difference between groups when considering the primary endpoint ( $44 \% v s .64 \%$ 
for percutaneous and surgical treatment, respectively; $P=0.01)$, especially when residual MR $(12.3 \% v s$. $1.8 \% ; P=0.02)$ and reoperation $(27.9 \%$ vs. $8.9 \% ; P=0.003)$ rates were examined ${ }^{[40]}$. However, the need for surgery after the index procedure occurred mainly in the first 6 months of follow-up (78\%) and mortality rates did not differ significantly at 5 years $(20.8 \%$ vs. $26.8 \% ; P=0.4)$. Unfortunately, it must be stated that the MitraClip cases included in this study were performed at the very beginning of the experience with this new percutaneous approach, thus the learning curve may have played a pivotal role affecting the outcomes reported.

In addition, the small amount of secondary MR patients reported in this study and the enrollment of operable patients only did not reflect the real-world scenario. Two registries, the ACCESS-EU in Northern Europe and the REALISM in United States, enrolled older patients with more comorbidities, mostly with ischemic MR and depressed $\operatorname{LVEF}^{[41]}$. More recently, two large randomized clinical trials analyzed specifically patients with secondary MR: the MITRA-FR and the COAPT trials. Despite randomization, these studies are still strongly debated by the scientific community for their contrasting outcomes. First, the MITRA-FR study enrolled severe symptomatic secondary MR patients (defined as effective regurgitant orifice area of $>20 \mathrm{~mm}^{2}$ or a regurgitant volume of $>30 \mathrm{~mL}$ per beat) with LV dysfunction (LVEF between $15 \%$ and $40 \%)$. After 1:1 randomization to medical therapy alone or medical therapy associated to percutaneous edge-to-edge repair, no difference was found in the primary composite outcome of any-cause death or unplanned hospitalization for heart failure at 1 year $(55 \% v s .51 \%$ for the intervention and the control group, respectively; OR: 1.16; 95\%CI: 0.73-1.84; $P=0.53)^{[42]}$.

Conversely, the COAPT trial showed opposite results. In this study 614 severe symptomatic secondary MR patients were 1:1 randomized to maximal doses of guideline-directed medical therapy $v s$. Mitraclip plus medical treatment ${ }^{[43]}$. Both primary and secondary endpoints at 24 months favored the MitraClip cohort, with a hospitalization rate for heart failure of $36 \% v s .68 \%$ per patient-year (HR: 0.53; 95\%CI: 0.40-0.70; $P<$ 0.001 ) and any-cause death rate of $29 \% v s .46 \%$ for device and control group, respectively (HR: 0.62; 95\%CI: $0.46-0.82 ; P<0.001)$.

Nevertheless, the contrasting results of these two trials can at least in part be explained by analyzing the major differences between them. The number of clips implanted per-patient was higher in the COAPT, which may justify the lower 1-year rate of severe residual MR as compared to MITRA-FR (5\% vs. 17\%, respectively). In addition, the COAPT Trial used the definition of ischemic MR severity according to the American Guidelines, resulting in more severe MR at baseline as compared to the MITRA-FR study, which enrolled the patients according to the European Guidelines (mean EROA $31 \mathrm{~mm}^{2} v s .41 \mathrm{~mm}^{2}$ ). Furthermore, indexed left ventricular end-diastolic volumes were larger in the MITRA-FR trial $\left(135 \pm 35 \mathrm{~mL} / \mathrm{m}^{2}\right.$ vs. $\left.101 \pm 34 \mathrm{~mL} / \mathrm{m}^{2}\right)$. Generally speaking, it seems that patients with more severe secondary MR and not very advanced LV remodeling/dysfunction, may benefit from MR correction/reduction when they remain symptomatic despite optimal guideline-directed medical therapy. Careful selection of the candidates to MitraClip therapy is therefore mandatory. As proposed by Grayburn et al ${ }^{[4]}$, the identification of proportionate or disproportionate MR could help in the decision-making process for the optimal treatment of secondary MR in patients with chronic heart failure and systolic dysfunction. Indeed, according to the Gorlin formula, patients of the MITRA-FR trial appeared to have proportionate MR since the severity of MR was proportionate to the degree of LV dilatation. Contrarily, participants of the COAPT trial had more severe MR (ERO 0.3-0.4 cm ${ }^{2}$ ) but less dilated LV (Left Ventricle End Diastolic Volume 160-200 mL), resulting in disproportionate MR. These specific and selected patients with disproportionate MR seemed to respond better to interventions targeting the mitral valve, like MitraClip. Finally, differences in adherence to optimal guideline-directed medical therapy may have played a role too in influencing the different results of these two studies. 


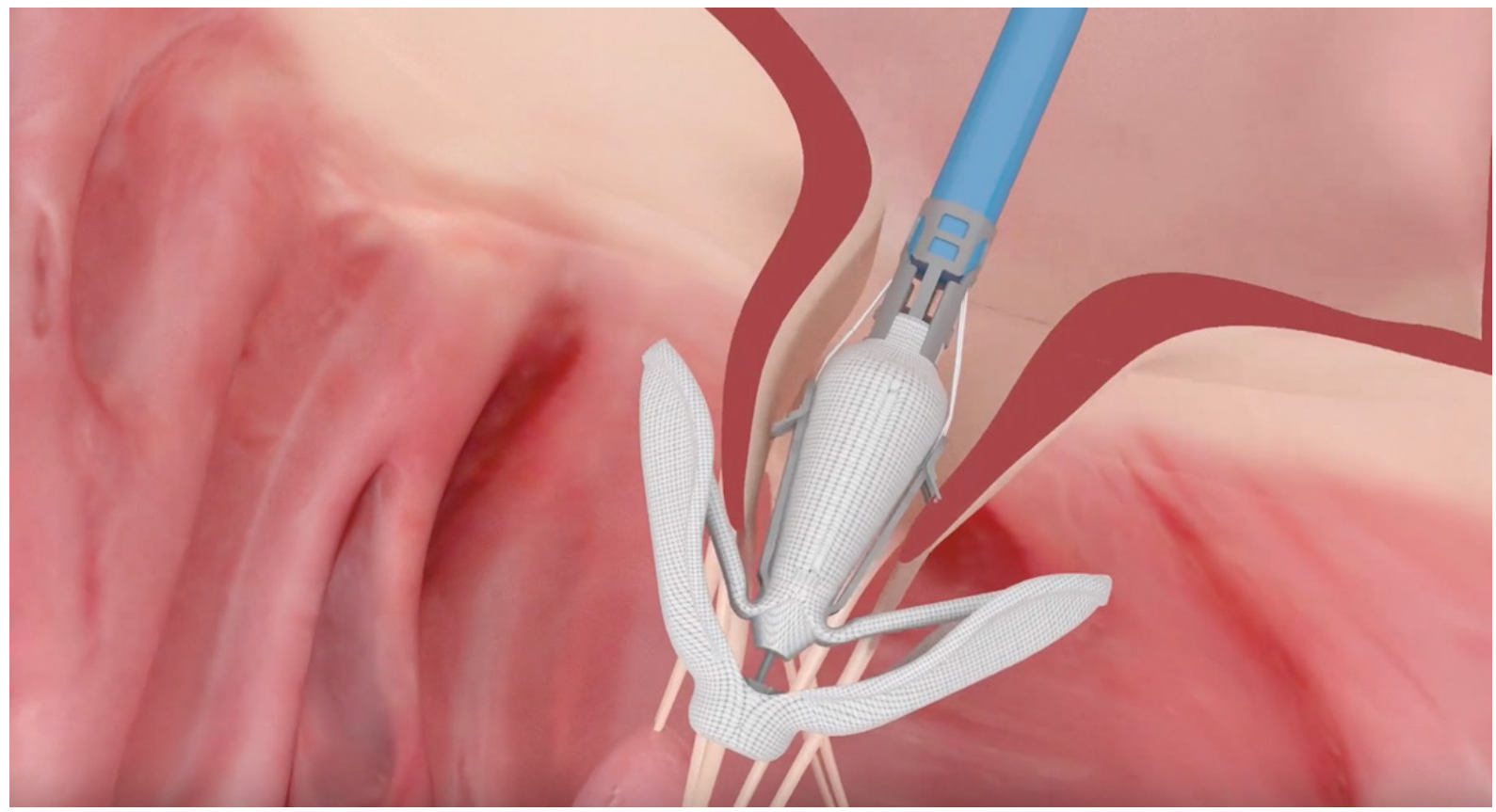

Figure 4. The PASCAL device. The image shows the percutaneous edge-to-spacer system approximating mitral leaflets (Courtesy of Edwards Lifesciences)

The most recent device developed to replicate the edge-to-edge technique is the PASCAL system (Edwards Lifesciences, Irvine, CA, USA), first implanted in 2016. It has obtained CE mark in early 2019, but it is still awaiting FDA approval. Its name, recalling the French scientist Blais Pascal, is linked to that of Professor Alfieri as well (from "Paddles, Spacer, Clasps, Alfieri"). Despite gross similarity to the MitraClip, it substantially differs from it since the mitral leaflets are approximated to the central spacer by using paddles and the grasping is provided by clasps (with a horizontal rather than vertical alignment). In this way, an "edge-to-spacer" repair can be performed with a lower level of tension on the leaflets [Figure 4]. In addition, the higher degree of steerability provides an enhanced navigation into the left heart, allowing independent grasping. This unique feature could be particularly useful in cases of large gaps and significant tethering.

The first-in-man study reported 23 compassionate cases, showing MR $\leq 2+$ in $97 \%$ of patients at discharge ${ }^{[45]}$. In 2019, Lim et al. ${ }^{[46]}$ reported the early outcome of 62 patients treated with PASCAL (CLASP study). Among them, 56\% suffered of functional, $36 \%$ of degenerative and $8 \%$ of mixed MR etiologies. At 30 days, $98 \%$ of patients showed $\mathrm{MR} \leq 2+$, all-cause mortality rate was $1.6 \%$ and there was no occurrence of strokes. A significant reduction of New York Heart Association class and improvement in quality of life were reported as well.

\section{CONCLUSION}

The introduction of the edge-to-edge technique almost 30 years ago has dramatically changed the world of mitral valve repair, not only from a surgical point of view, but also (and even more) from the percutaneous perspective. This simple and versatile surgical gesture has been adopted in a variety of pathologies on thousands of patients. It has also laid the foundations for the percutaneous correction of mitral regurgitation. In other words, it has represented a true milestone in the history of cardiac surgery and, probably, it will keep playing a pivotal role in the future of technological innovations. 


\section{DECLARATIONS}

\section{Authors' contributions}

Drafted the manuscript: Belluschi I, Buzzatti N

Made substantial contributions in conceptualization and revision of the manuscript: Castiglioni C, Alfieri O,

De Bonis $\mathrm{M}$

\section{Availability of data and materials}

Not applicable.

\section{Financial support and sponsorship}

The Alfieri Heart Foundation supported conceptualization of this review.

\section{Conflicts of interest}

The mitral valve repair edge-to-edge technique described in this review was introduced by Prof. Ottavio Alfieri who is a Co-author of this manuscript.

\section{Ethical approval and consent to participate}

Not applicable.

\section{Consent for publication}

Not applicable.

\section{Copyright}

C The Author(s) 2020.

\section{REFERENCES}

1. Nkomo VT, Gardin JM, Skelton TN, Gottdiener JS, Scott CG, et al. Burden of valvular heart diseases: a population-based study. Lancet 2006;368:1005-11.

2. Baumgartner H, Falk V, Bax JJ, De Bonis M, Hamm C, et al; ESC Scientific Document Group. 2017 ESC/EACTS Guidelines for the management of valvular heart disease. Eur Heart J 2017;38:2739-91.

3. Carpentier A. Cardiac valve surgery--the "French correction". J Thorac Cardiovasc Surg. 1983;86:323-37.

4. Braunberger E, Deloche A, Berrebi A, Abdallah F, Celestin JA, et al. Very long-term results (more than 20 years) of valve repair with carpentier's techniques in nonrheumatic mitral valve insufficiency. Circulation 2001;104:I8-11.

5. Flameng W, Herijgers P, Bogaerts K. Recurrence of mitral valve regurgitation after mitral valve repair in degenerative valve disease. Circulation 2003;107:1609-13.

6. Maisano F, Torracca L, Oppizzi M, Stefano P, D'addario G, et al. The edge-to-edge technique: a simplified method to correct mitral insufficiency. Eur J Cardiothorac Surg 1998;13:240-6.

7. Fucci C, Cicco GD, Chiari E, Nardi M, Faggiano P, et al. Edge-to-edge mitral valve repair for isolated prolapse of the anterior leaflet caused by degenerative disease. J Cardiovasc Med (Hagerstown) 2007;8:354-8.

8. Gillinov AM, Cosgrove DM. Mitral valve repair for degenerative disease. J Heart Valve Dis 2002;11:S15-20.

9. Raman J, Shah P, Seevanayagam S, Cheung J, Buxton B. Mitral regurgitation: comparison between edge-to-edge repair and valve replacement. Asian Cardiovasc Thorac Ann 2003;11:131-4.

10. Kherani AR, Cheema FH, Casher J, Fal JM, Mutrie CJ, et al. Edge-to-edge mitral valve repair: the Columbia Presbyterian experience. Ann Thorac Surg 2004;78:73-6.

11. Bhudia SK, McCarthy PM, Smedira NG, Lam BK, Rajeswaran J, et al. Edge-to-edge (Alfieri) mitral repair: results in diverse clinical settings. Ann Thorac Surg 2004;77:1598-606.

12. Brinster DR, Unic D, D’Ambra MN, Nathan N, Cohn LH. Midterm results of the edge-to-edge technique for complex mitral valve repair. Ann Thorac Surg 2006;81:1612-7.

13. Myers PO, Khalpey Z, Maloney AM, Brinster DR, D’Ambra MN, et al. Edge-to-edge repair for prevention and treatment of mitral valve systolic anterior motion. J Thorac Cardiovasc Surg 2013;146:836-40.

14. De Bonis M, Alfieri O. The edge-to-edge technique for mitral valve repair. HSR Proc Intensive Care Cardiovasc Anesth 2010;2:7-17.

15. Daneshmand MA, Milano CA, Rankin JS, Honeycutt EF, Swaminathan M, et al. Mitral valve repair for degenerative disease: a 20-year experience. Ann Thorac Surg 2009;88:1828-37. 
16. David TE, Armstrong S, McCrindle BW, Manlhiot C. Late outcomes of mitral valve repair for mitral regurgitation due to degenerative disease. Circulation 2013;127:1485-92.

17. Magne J, Sénéchal M, Dumesnil JG, Pibarot P. Ischemic mitral regurgitation: a complex multifaceted disease. Cardiology 2009;112:244-59.

18. Lancellotti P, Moura L, Pierard LA, Agricola E, Popescu BA, et al; European Association of Echocardiography. European Association of Echocardiography recommendations for the assessment of valvular regurgitation. Part 2: mitral and tricuspid regurgitation (native valve disease). Eur J Echocardiogr 2010;11:307-32.

19. Alfieri O, Maisano F, De Bonis M, Stefano PL, Torracca L, et al. The double-orifice technique in mitral valve repair: a simple solution for complex problems. J Thorac Cardiovasc Surg 2001;122:674-81.

20. De Bonis M, Lapenna E, Maisano F, Barili F, La Canna G, et al. Long-term results ( $\leq 18$ years) of the edge-to-edge mitral valve repair without annuloplasty in degenerative mitral regurgitation: implications for the percutaneous approach. Circulation 2014;130:S19-24.

21. Agricola E, Maisano F, Oppizzi M, De Bonis M, Torracca L, et al. Mitral valve reserve in double-orifice technique: an exercise echocardiographic study. J Heart Valve Dis 2002;11:637-43.

22. Frapier JM, Sportouch C, Rauzy V, Rouviere P, Cade S, et al. Mitral valve repair by Alfieri's technique does not limit exercise tolerance more than Carpentier's correction. Eur J Cardiothorac Surg 2006;29:1020-5.

23. Maisano F, Schreuder JJ, Oppizzi M, Fiorani B, Fino C, et al. The double-orifice technique as a standardized approach to treat mitral regurgitation due to severe myxomatous disease: surgical technique. Eur J Cardiothorac Surg 2000;17:201-5.

24. De Bonis M, Lapenna E, Lorusso R, Buzzatti N, Gelsomino S, et al. Very long-term results (up to 17 years) with the double-orifice mitral valve repair combined with ring annuloplasty for degenerative mitral regurgitation. J Thorac Cardiovasc Surg 2012;144:1019-24.

25. Gillinov AM, Blackstone EH, Alaulaqi A, Sabik JF 3rd, Mihaljevic T, et al. Outcomes after repair of the anterior mitral leaflet for degenerative disease. Ann Thorac Surg 2008;86:708-17; discussion 708-17.

26. De Bonis M, Lapenna E, Taramasso M, La Canna G, Buzzatti N, et al. Very long-term durability of the edge-to-edge repair for isolated anterior mitral leaflet prolapse: up to 21 years of clinical and echocardiographic results. J Thorac Cardiovasc Surg 2014;148:2027-32.

27. Lapenna E, De Bonis M, Sorrentino F, La Canna G, Grimaldi A, et al. Commissural closure for the treatment of commissural mitral valve prolapse or flail. J Heart Valve Dis 2008;17:261-6.

28. Gillinov AM, Shortt KG, Cosgrove DM 3rd. Commissural closure for repair of mitral commissural prolapse. Ann Thorac Surg 2005;80:1135-6.

29. De Bonis M, Lapenna E, La Canna G, Ficarra E, Pagliaro M, et al. Mitral valve repair for functional mitral regurgitation in end-stage dilated cardiomyopathy: role of the "edge-to-edge" technique. Circulation 2005;112:I402-8.

30. Mascagni R, Al Attar N, Lamarra M, Calvi S, Tripodi A, et al. Edge-to-edge technique to treat post-mitral valve repair systolic anterior motion and left ventricular outflow tract obstruction. Ann Thorac Surg 2005;79:471-3; discussion 474.

31. Lapenna E, Nisi T, Ruggeri S, Trumello C, Del Forno B, et al. Edge-to-edge mitral repair associated to septal myectomy in hypertrophic obstructive cardiomyopathy. Ann Thorac Surg 2020; doi: 10.1016/j.athoracsur.2020.03.095.

32. Gatti G, Cardu G, Trane R, Pugliese P. The edge-to-edge technique as a trick to rescue an imperfect mitral valve repair. Eur J Cardiothorac Surg 2002;22:817-20.

33. De Bonis M, Lapenna E, Buzzatti N, Taramasso M, Calabrese MC, et al. Can the edge-to-edge technique provide durable results when used to rescue patients with suboptimal conventional mitral repair? Eur J Cardiothorac Surg 2013;43:e173-9.

34. Javadikasgari H, Suri RM, Mihaljevic T, Mick S, Gillinov AM. Technical aspects of robotic posterior mitral valve leaflet repair. Ann Cardiothorac Surg 2016;5:577-81.

35. Belluschi I, Lapenna E, Blasio A, Del Forno B, Giacomini A, et al. Excellent long-term results with minimally invasive edge-to-edge repair in myxomatous degenerative mitral valve regurgitation. Interact Cardiovasc Thorac Surg 2020;31:28-34.

36. Maisano F, La Canna G, Colombo A, Alfieri O. The evolution from surgery to percutaneous mitral valve interventions: the role of the edge-to-edge technique. J Am Coll Cardiol 2011;58:2174-82.

37. Fann JI, St Goar FG, Komtebedde J, Oz MC, Block PC, et al. Beating heart catheter-based edge-to-edge mitral valve procedure in a porcine model: efficacy and healing response. Circulation 2004;110:988-93.

38. Feldman T, Wasserman HS, Herrmann HC, Gray W, Block PC, et al. Percutaneous mitral valve repair using the edge-to-edge technique: six-month results of the EVEREST Phase I Clinical Trial. J Am Coll Cardiol 2005;46:2134-40.

39. Feldman T, Foster E, Glower DD, Kar S, Rinaldi MJ, et al; EVEREST II Investigators. Percutaneous repair or surgery for mitral regurgitation. N Engl J Med 2011;364:1395-406.

40. Feldman T, Kar S, Elmariah S, Smart SC, Trento A, et al; EVEREST II Investigators. Randomized comparison of percutaneous repair and surgery for mitral regurgitation: 5-year results of EVEREST II. J Am Coll Cardiol 2015;66:2844-54.

41. Maisano F, Franzen O, Baldus S, Schäfer U, Hausleiter J, et al. Percutaneous mitral valve interventions in the real world: early and 1-year results from the ACCESS-EU, a prospective, multicenter, nonrandomized post-approval study of the MitraClip therapy in Europe. J Am Coll Cardiol 2013;62:1052-61.

42. Obadia JF, Messika-Zeitoun D, Leurent G, Iung B, Bonnet G, et al; MITRA-FR Investigators. Percutaneous repair or medical treatment for secondary mitral regurgitation. N Engl J Med 2018;379:2297-306.

43. Stone GW, Lindenfeld J, Abraham WT, Kar S, Lim DS, et al; COAPT Investigators. Transcatheter mitral-valve repair in patients with heart failure. N Engl J Med 2018;379:2307-18.

44. Grayburn PA, Sannino A, Packer M. Proportionate and disproportionate functional mitral regurgitation: a new conceptual framework that reconciles the results of the MITRA-FR and COAPT trials. JACC Cardiovasc Imaging 2019;12:353-62.

45. Praz F, Spargias K, Chrissoheris M, Büllesfeld L, Nickenig G, et al. Compassionate use of the PASCAL transcatheter mitral valve repair 
system for patients with severe mitral regurgitation: a multicentre, prospective, observational, first-in-man study. Lancet 2017;390:773-80.

46. Lim DS, Kar S, Spargias K, Kipperman RM, O’Neill WW, et al. Transcatheter valve repair for patients with mitral regurgitation: 30-day results of the CLASP study. JACC Cardiovasc Interv 2019;12:1369-78. 